\title{
THE COMPARISON OF LABORATORY TESTS AND NUMERICAL ANALYSIS OF PRESSURE AND TENSION BEARING CAPACITIES OF THE NEW SYSTEM OF MICROBULB AND MICROPILE SYSTEM ON CLAY IN SHIRAZ, IRAN
}

\author{
HAKIMIAN Saeed ${ }^{a}$, MOSALLANEZHAD Mansour ${ }^{\text {b, }}$ * \\ ${ }^{a}$ Islamic Azad University (Estahban Branch), Iran, e-mail: saeedhakimian@yahoo.com \\ b* Shiraz University, Department of Civil and Environmental Engineering, Iran, e-mail: mmosalla@shirazu.ac.ir
}

Received: 06.04.2018 / Accepted: 27.07.2018 / Revised: 26.04.2019 / Available online: 31.05.2019

DOI: 10.2478/jaes-2019-0008

KEY WORDS: micropile, microbulb, bearing capacity, plaxis 3D Foundation.

\begin{abstract}
:
In recent years, the implementations of Micropiles have been increased extensively in large project constructions due to the unique advantages of this method comparing to concrete piles. The results of numerical analysis and centrifuge tests show that the efficiency and importance of micropiles can be considered as an effective solution. This research is designed to compare the newly designed system of microbulb with micropile applying a numerical modeling with finite element software Plaxis 3D foundation v1.6. We also used the FHWA code for a comparative study between micropiles and microbulbs. Then the effective factors were analyzed in order to decide which method is better between these two methods of micropile and microbulb. The results showed that the new microbulb system is an appropriate solution for improvement of mechanical properties of the soil, increase of bearing capacity and settlement decrease.
\end{abstract}

\section{INTRODUCTION}

Using micropiles in foundations began effectively since 1950. Micropile is a metal pipe of $300 \mathrm{~mm}$, which is drilled or placed in the desired depth of land, and then the grouting operations, including cement grouting, water and other various additive grouting will be applied. Considering the depth and gender profiles of the ground, the grout is injected under pressure of 5 to 25 times. Micropiles are applied effectively to improve the mechanical properties of soil, increase bearing capacity and to reduce possible settlement especially for retrofitting of foundation constructions.

Micropiles, like other geotechnical elements have both geotechnical capacity and bearing capacity. Micropile's geotechnical bearing capacity is supplied mainly through interface friction and concrete links made by grout injection around the micropiles. Structural bearing capacity of in-situ piles is provided by the increase of cross-sectional area while bearing capacity of micropiles is provided mainly by steel elements of micropiles. This steel element covers about half of the borehole (Tom Armour, 2000) Micropile's bearing capacity contains an extensive range according to the relations, which are recommended in the references. These relations result in different bearings with regard to the method of application and type of soil. Recommended values of safety factor in order to determine bearing capacity of micropile are available in the FHWA 2.5 regulations (Lizzi, 1985).

\section{HISTORICAL BACKGROUND OF MICROPILE}

Lizzi used micropiles for the first time as a method in 1950 in Italy in order to repair the foundations of historical buildings, which were damaged during the worldwide two.

This technology was spread very fast in the world, and some countries such as England, Germany and North America started to use this method in 1962, 1965 and 1973. China's first attempt of using this technology was in 1980 in order to protect the deviation of the $\mathrm{Hu}$ - Qiu tower that was built in the year 959.

Lizzi and Plumele (1984) showed that use of micropiles creates a reinforced soil system with adhesion and will result in increasing the soil mechanical parameters. In 1973, FHWA supported a comprehensive investigation in relation to micropiles. The research group presented a comprehensive guide about how to impellent micropiles using the international research background, the laboratory results and the designed methods (Stuedlein, 2008).

\footnotetext{
* Corresponding author. Mansour Mosalla Nejad, e-mail: Mmosalla@ shirazu.ac.ir
} 


\section{MICROBULB}

Microbulb structure sharing all effective properties of the micropiles, has a number of differences with them. These differences cause changes, which lead to an increase in loading capacity and a decrease in movement and settlement. Generally, the process is as follow, injection applies with the specified biometric pressure, the grout moves through the holes of microbulb body and enters into a rubber membrane layer, and then the grout enters the second membrane layer and stands between the two membrane layers. It should be mentioned that the membrane layer has been tightened with steel clamps. The grout is not allowed to pass the second layer and the second layer, which has an elastic quality, starts to swell. Then a bulb forms which overthrows and compress the soil around it. After that, some bulb shaped grout forms. These bulbs have effects on increase of pressure bearing capacity, tension bearding capacity and decrease of settlement (Figure 1).

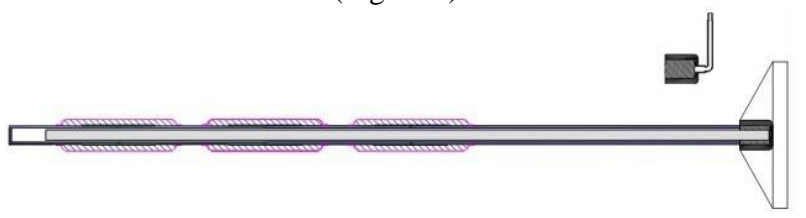

Figure 1. Test box

\section{LABORATORY TESTS}

In order to complete the laboratory tests (Figure 2 and Figure 3), 12 microbulb was made, then a box was designed and made for tests with the size of 1 meter $\times 1 / 5$ meter and with the height of 2 meters, then layers of clay with $10 \mathrm{~cm}$ thickness and density of $92,88,81$ was poured in the box. Later, some holes were designed in soil's profile using a manual lift and then micropiles and microbulbs were placed in the holes.

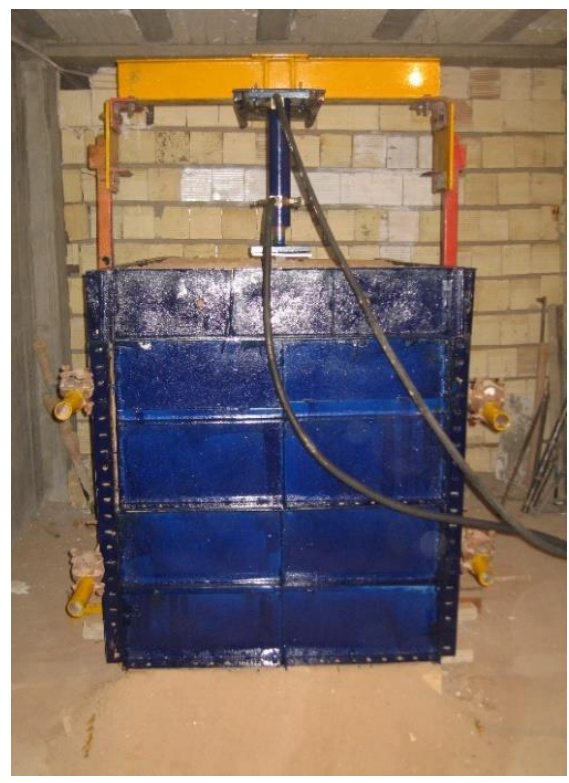

Figure 2. Box of tests

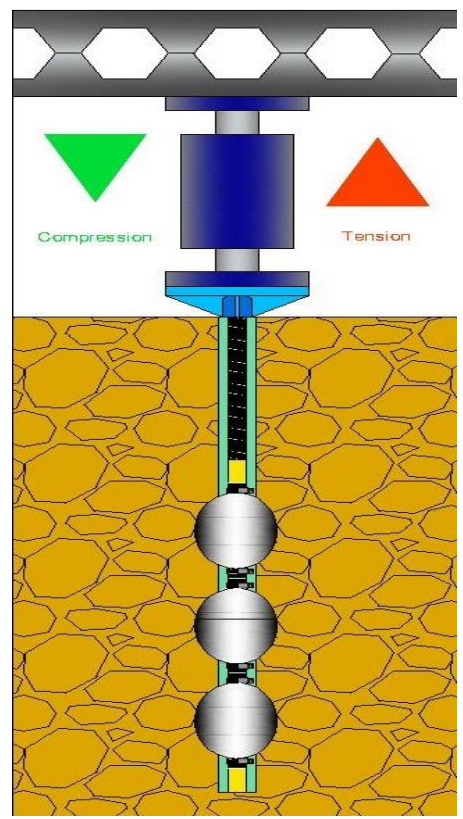

Figure 3. Pressure and tension test of microbulb

The following diagrams (Figures 4-13) show the results of laboratory tests on the tension and the pressure bearing capacity of micropiles and microbulbs.

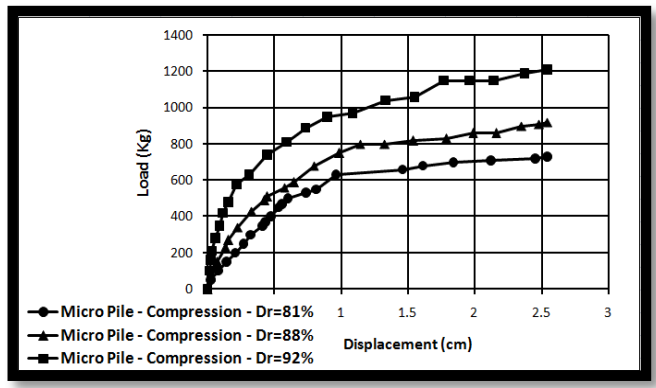

Figure 4. Laboratory test of pressure bearing capacity on micropile with three different percentage of densities equal to $81,88,92$

As we can see, (Figure 4) shows that the pressure bearing capacity of micropile with 3 various densities of $81,88,92$, increased as the percent of soil density increases.

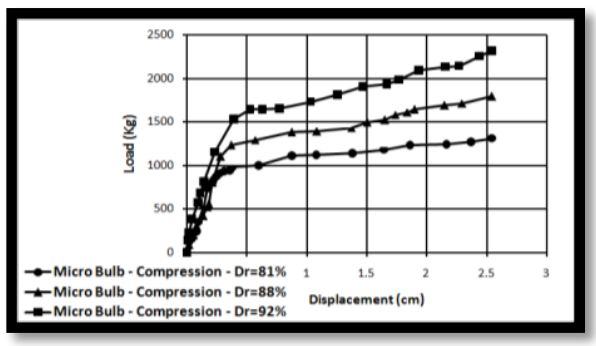

Figure 5. Laboratory test of pressure bearing capacity on microbulb with 3 densities of $81,88,92$ percent 
As it is shown in (Figure 5), the pressure bearing capacity of microbulbs with 3 various densities of $81,88,92$ is increased as the percent of the soil density increases

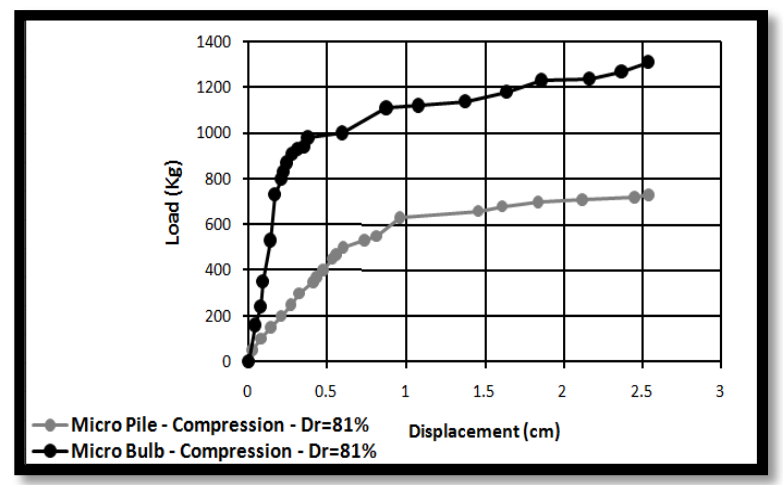

Figure 6. Comparison of pressure bearing capacity of micropiles and of microbulb with a density of $81 \%$

(Figure 6) shows the pressure bearing capacity test of micropile in comparison with microbulb with a density of $81 \%$, the result shows that pressure bearing capacity of microbulb is more than of micropile and the increased amount is bout two times.

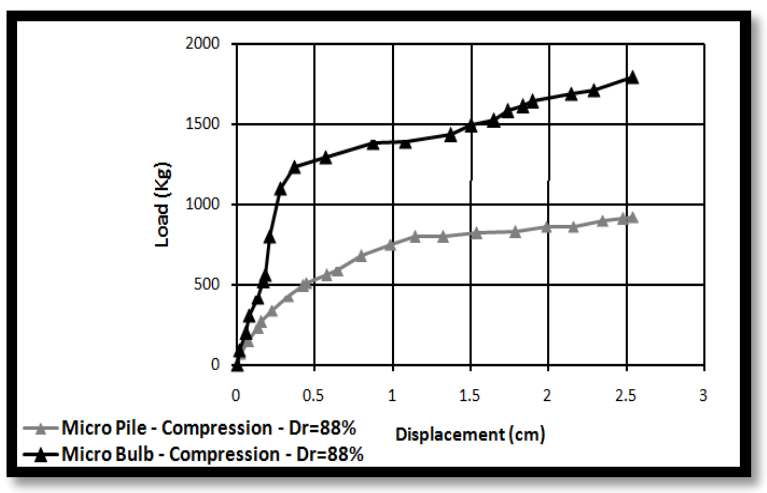

Figure 7. Comparison of pressure bearing capacity of micropiles and of microbulb with a density of $88 \%$

(Figure 7) shows the pressure bearing capacity test of micropile in comparison with microbulb with density of $88 \%$, the result shows that pressure bearing capacity of microbulb is more than of micropile and the increased amount is bout two times.

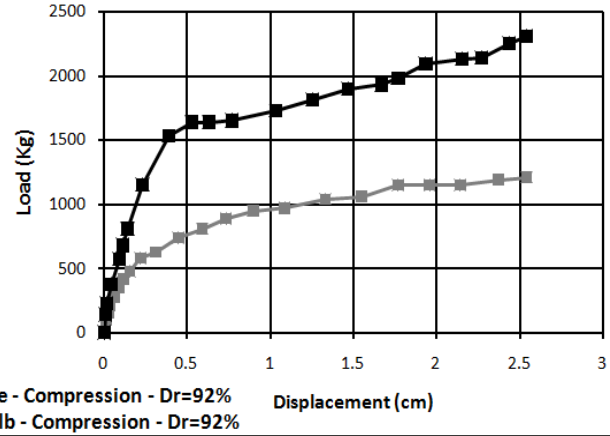

Figure 8. Comparison of pressure bearing capacity of micropiles and of microbulb with a density of $92 \%$

(Figure 8) shows the pressure bearing capacity test of micropile in comparison with microbulb with a density of $92 \%$, the result shows that pressure bearing capacity of microbulb is more than of micropile and the increased amount is bout two times.

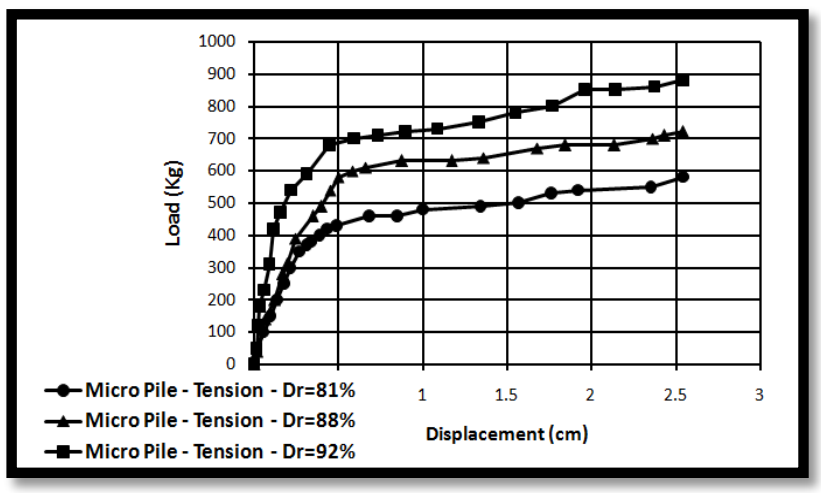

Figure 9. Laboratory test of tension bearing capacity of micropile with 3 different densities of $81,88,92$ percent

As (Figure 9) shows in the laboratory test of micropile's tension bearing capacity with 3 different densities of $81,88,92$ we can say that pressure bearing capacity increases with the increase of percentage of soil density.

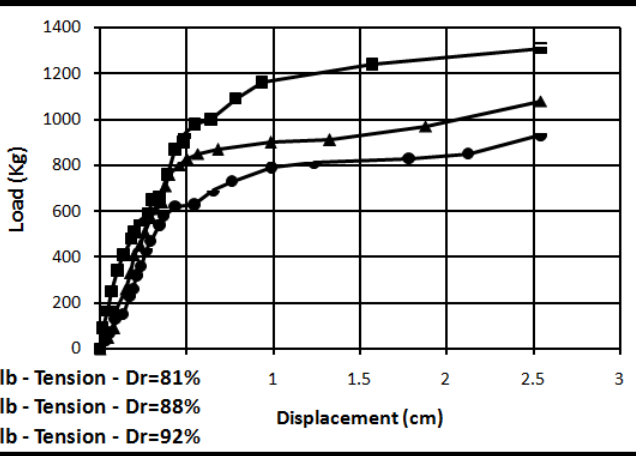

-Micro Bulb - Tension - Dr=88\%

$\rightarrow-$ Micro Bulb - Tension - Dr=92\%

Displacement $(\mathrm{cm})$

Figure 10. Laboratory test of tension bearing capacity of microbulb with 3 different densities of $81,88,92$ percent 
As (Figure 10) shows in the laboratory test of microbulb's tension bearing capacity with 3 different densities of $81,88,92$ we can say that pressure bearing capacity increases with the increase of percent of soil density.

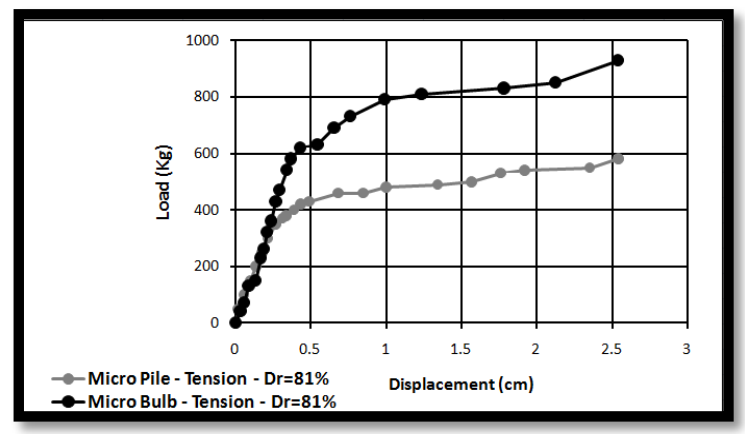

Figure 11. Comparison of laboratory tests for tension bearing capacity of micropile and microbulb with 81 percent of soil density

(Figure 11) shows a laboratory test of tension bearing capacity of micropile and microbulb in soil with a density of 81 , we can conclude from this figure that tension bearing capacity of microbulb is greater about 1.6 times in comparison to micropile.

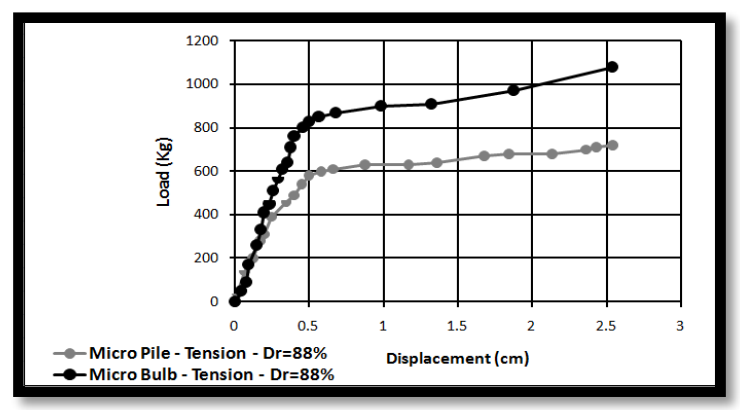

Figure 12. Comparison of laboratory tests for tension bearing capacity of micropile and of microbulb with 88 percent of soil density

As it is shown in (Figure 12), the result of a laboratory test of tension bearing capacity of micropile and of microbulb in soil with the density of 88 , shows that tension bearing capacity of microbulb is greater about 1.6 time in comparison to micropile in (Figure 13)..

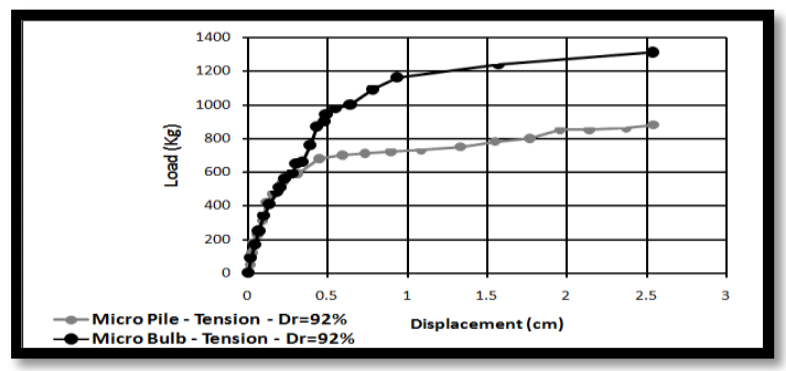

Figure 13. Comparison of laboratory tests for tension bearing capacity of micropile and microbulb with 92 percent of soil density

\section{LABORATORY TESTS}

A three dimensional model of Plaxis 3D foundation v1. 6 was used in order to examine the micropile system. The Plaxis program development began in 1987 at the University of Delft in the Netherlands. The three-dimensional Plaxis program uses specifically for review and analysis of piles and offshore foundations. The soil model in this study was prepared in dimensions of $1 \mathrm{~m}, 1.5 \mathrm{~m}$ and height of $1.2 \mathrm{~m}$.The length and diameter of the micropile were considered respectively 1 meter and 1 inch. (Figure 14) shows the modeled micropile in the soil profile.
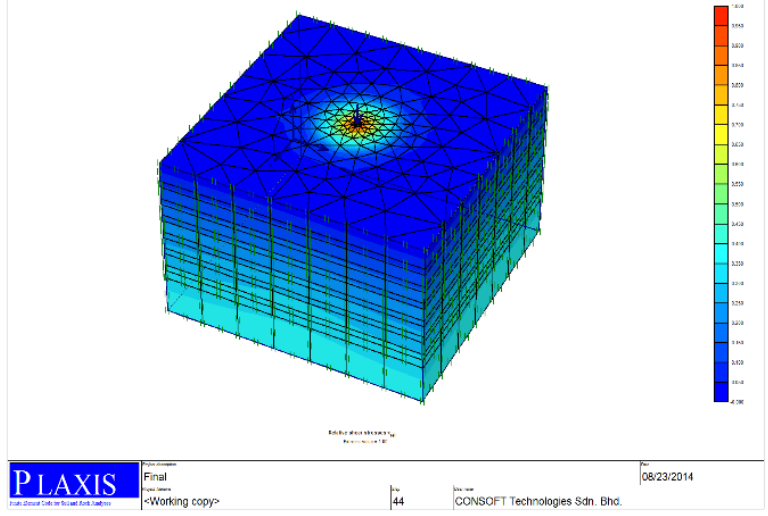

Figure 14. Modeled Microbulb in soil profile

The microbulb was modeled with 1-meter length and the diameter of $9 \mathrm{~cm}$. In this analysis, the Mohr-Coulomb behavioral model was used for the soil, and the EL linear elastic model for the micropile element. Table 1 shows, geotechnical parameters, soil properties, micropile and microbulb (Figure 15).

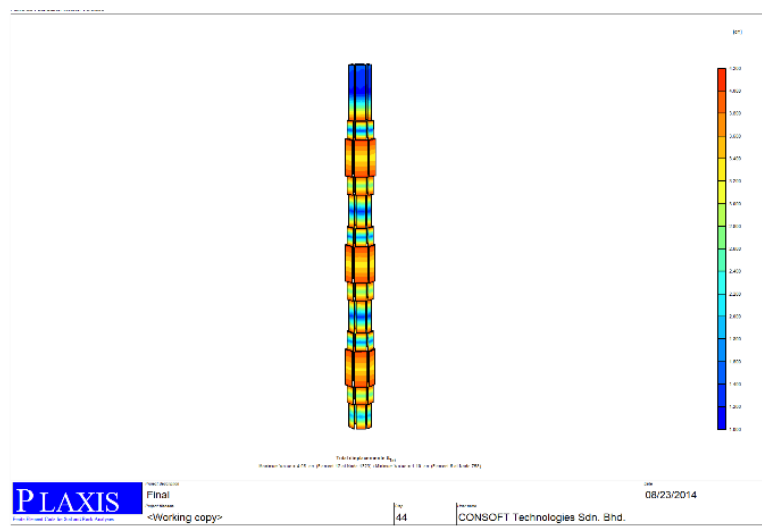

Figure 15. Modeled Microbulb in soil profile

\section{THE PROGRAM OPERATION}

By selecting the desired mechanical properties suitable for the soil, and by performing the numerical analysis of the loading capacity diagram of micropile and microbulb after the deformations, the loading diagram was drawn. (Figure 16) shows 
the overall movement counters of modeled microbulb in the soil profile.

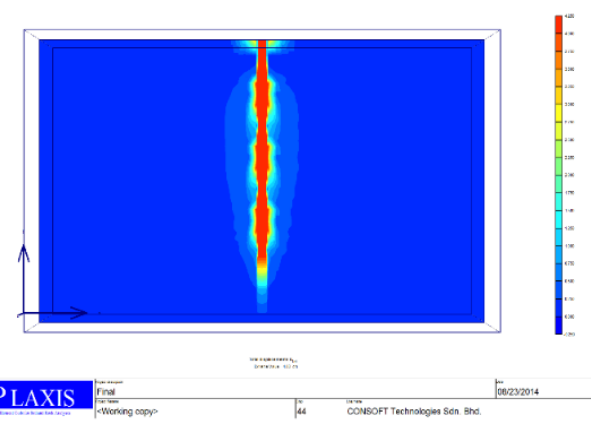

Figure 16. The overall movement counters of modeled microbulb in soil profile

The following figures (Figures 17-26) shows the results of numerical analysis of pressure bearing capacity of micropiles with a 3 various densities of $81,88,92$ percent.

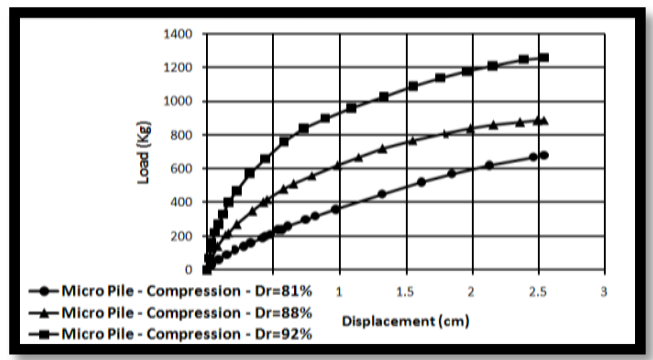

Figure 17. Numerical analysis of pressure bearing capacity of micropile with 3 various densities of $81,88,92$

As it is obvious in (Figure 17) in a numerical test of micropile's pressure bearing capacity with 3 different densities of $81,88,92$, the pressure bearing capacity increases by increase of soil density percent.

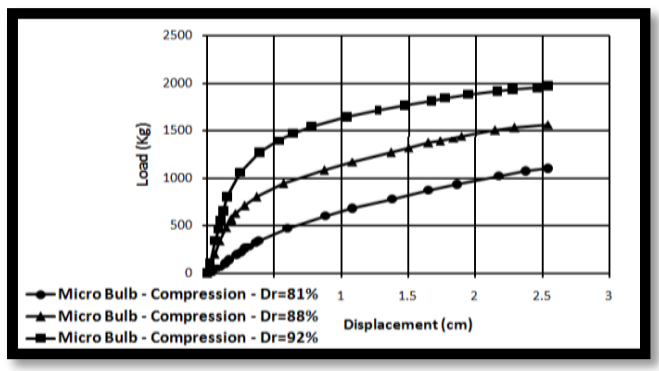

Figure 18. Numerical analysis of pressure bearing capacity of microbulb with 3 different density of $81,88,92$

(Figure 18) shows that in numerical tests of micropile with 3 different densities of $81,88,92$, the pressure bearing capacity increases with increase of soil density percent.

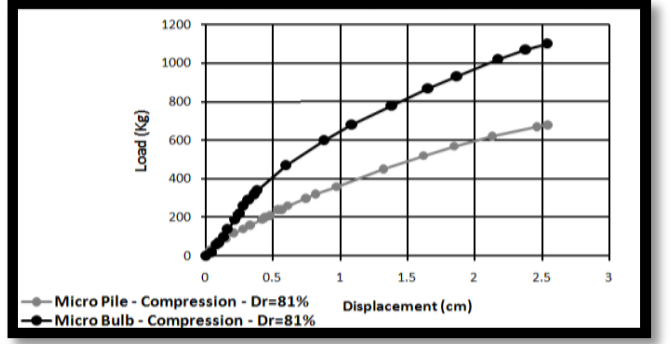

Figure 19. Comparison of pressure bearing capacity of micropile and of microbulb for 81 percent of density

(Figure 19) shows the comparison of numerical analysis for pressure bearing capacity of micropile and microbulb with a density of 81 percent, the result of this test reveals that pressure bearing capacity of microbulb is higher than micropile for an amount equal to 1.8 times.

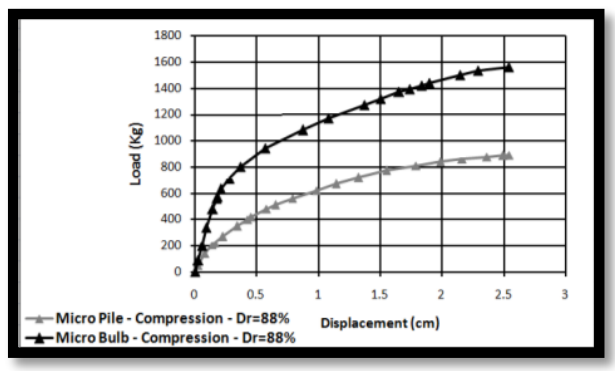

Figure 20. Comparison of pressure bearing capacity of micropile and of microbulb for 88 percent of density

(Figure 20) shows the comparison of numerical analysis for pressure bearing capacity of micropile and microbulb with a density of 88 percent, the result of this test reveals that pressure bearing capacity of microbulb is higher than of microple for an amount equal to 1.8 times.

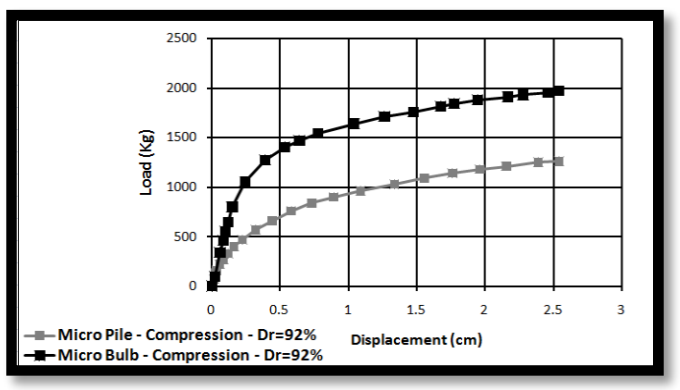

Figure 21. Comparison of pressure bearing capacity of micropile and microbulb for 92 percent of density

(Figure 21) shows the comparison of numerical analysis for pressure bearing capacity of micropile and microbulb with a density of 92 percent, the result of this test reveals that pressure bearing capacity of microbulb is higher than of micropile for an amount equal to 1.8 times. 


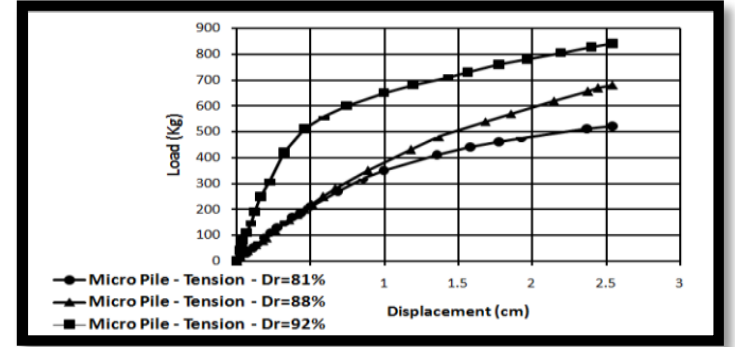

Figure 22. Numerical analysis of tension bearing capacity of micropile with 3 different densities of $81,88,92$

(Figure 22) shows that in numerical tests of micropile with 3 different density of $81,88,92$, the tension bearing capacity increases with increase of soil density percent.

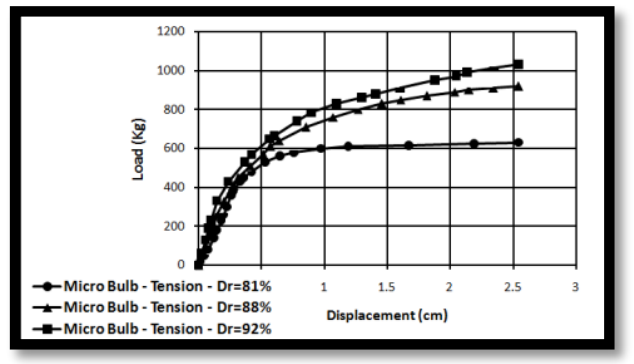

Figure 23. Numerical analysis of tension bearing capacity of microbulb with 3 different density of $81,88,92$

(Figure 23) shows that in numerical tests of microbulb with 3 different densities of $81,88,92$, the tension bearing capacity increases with increase of soil density percent

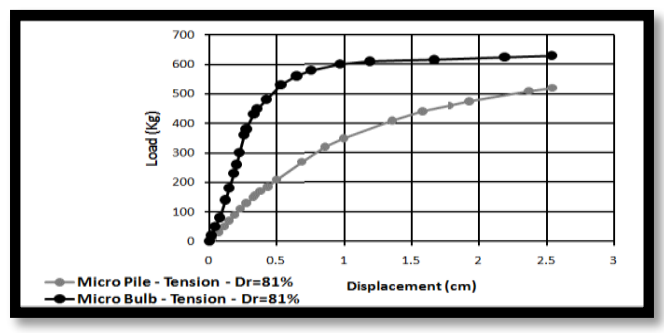

Figure 24. Comparison of pressure,tension capacity of micropile and microbulb for 81 percent of density

(Figure 24) shows the comparison of numerical analysis for tension bearing capacity of micropile and microbulb with a density of 81 percent, the result of this test reveals that pressure bearing capacity of microbulb is higher than of micropile for an amount equal to 1.2 times.

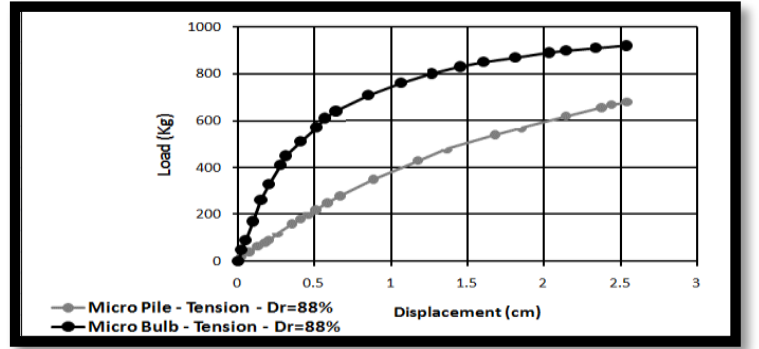

Figure 25. Comparison of tension bearing capacity of micropile and microbulb for 88 percent of density

(Figure 25) shows the comparison of numerical analysis for tension bearing capacity of micropile and microbulb with a density of 88 percent, the result of this test reveals that pressure bearing capacity of microbulb is higher than of micropile for an amount equal to 1.4 times.

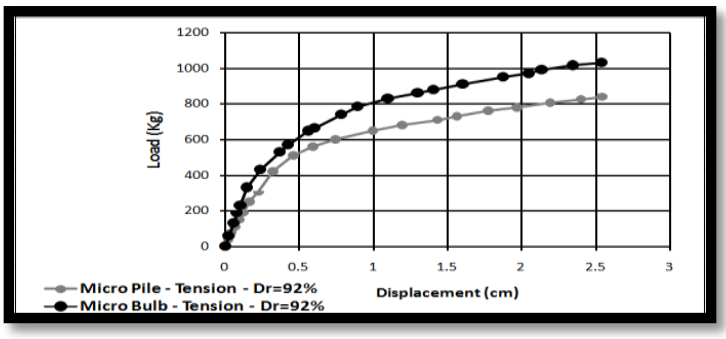

Figure 26. Comparison of tension bearing capacity of micropile and of microbulb for 92 percent of density

(Figure 26) shows the comparison of numerical analysis for tension bearing capacity of micropile and microbulb with density of 92 percent, the result of this test reveals that pressure bearing capacity of microbulb is higher than of micropile for an amount equal to 1.3 times.

\section{RESULTS REVIEW AND THE COMPARISON BETWEEN BEARING CAPACITY OF MICROPILE AND MICROBULB}

Having finished the calculation process after assigning initial conditions of material and loading, the loading diagrams for micropile and microbulb were completed and they are shown in the following (Figures 27-38).

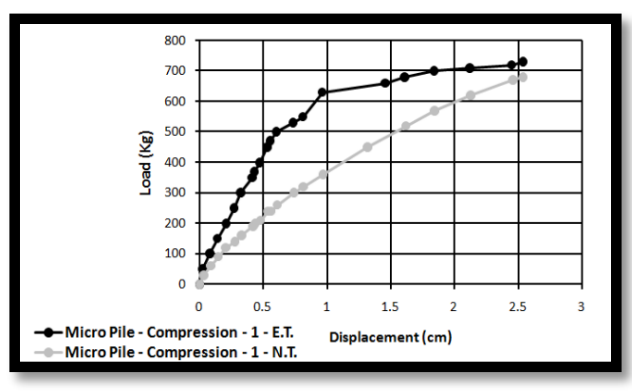


As we can see in (Figure 27), the comparison of laboratory test and numerical test of pressure bearing capacity of micropile with a density of 81 percent shows that the numerical diagram is the normalized form of laboratory diagram. Therefore,we can conclude that with the increase of amount of displacement and loading ,the diagram for numerical test gets closer to the laboratory test diagram.

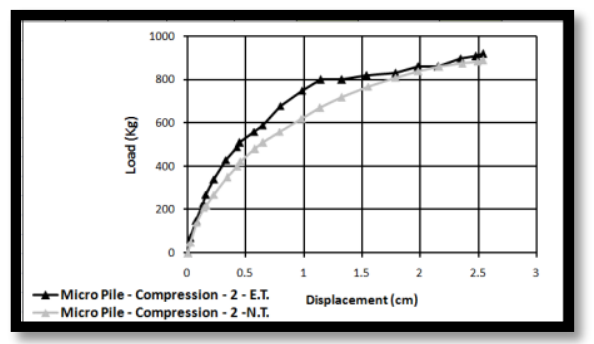

Figure 28. Comparison of laboratory test and numerical analysis of pressure bearing capacity of micropile in soil with a density of 88 percent

As we can see in (Figure 28), the comparison of laboratory test and numerical test of pressure bearing capacity of micropile with a density of 88 percent shows that the numerical diagram is the normalized form of laboratory diagram. Therefore, we can conclude that with the increase of amount of displacement and loading, the diagram for numerical test gets closer to the laboratory test diagram.

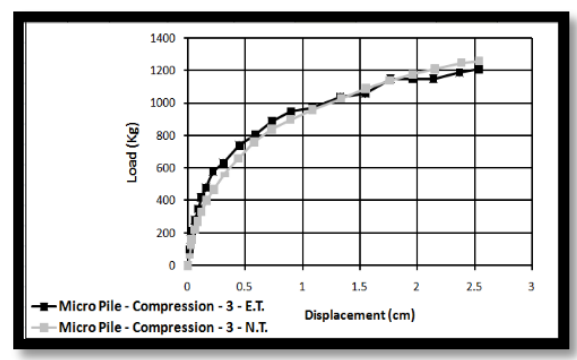

Figure 29. Comparison of laboratory test and numerical analysis of pressure bearing capacity of micropile in soil with a density of 92 percent

As we can see in (Figure 29), the comparison of laboratory test and numerical test of pressure bearing capacity of micropile with a density of 92 percent shows that the numerical diagram is the normalized form of laboratory diagram. Therefore, we can conclude that with the increase of amount of displacement and loading, the diagram for numerical test gets closer to the laboratory test diagram.

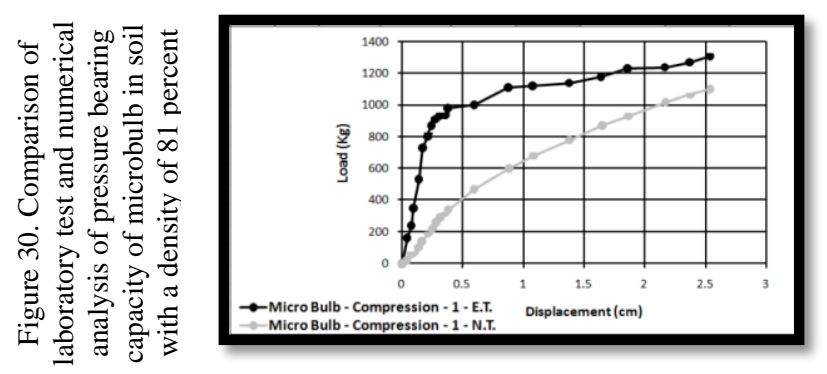

As we can see in (Figure 30), the comparison of laboratory test and numerical test of pressure bearing capacity of microbulb with a density of 81 percent shows that the numerical diagram is the normalized form of laboratory diagram. Therefore, we can conclude that with the increase of amount of displacement and loading, the diagram for numerical test gets closer to the laboratory test diagram.

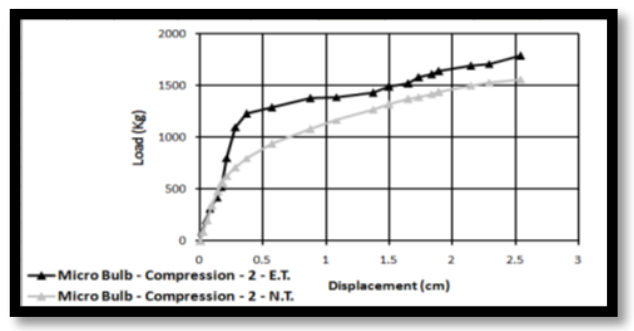

Figure 31. Comparison of laboratory test and numerical analysis of pressure bearing capacity of micropile in soil with a density of 88 percent

As we can see in (Figure 31), the comparison of laboratory test and numerical test of pressure bearing capacity of microbulb with a density of 88 percent shows that the numerical diagram is the normalized form of laboratory diagram. Therefore, we can conclude that with the increase of amount of displacement and loading, the diagram for numerical test gets closer to the laboratory test diagram.

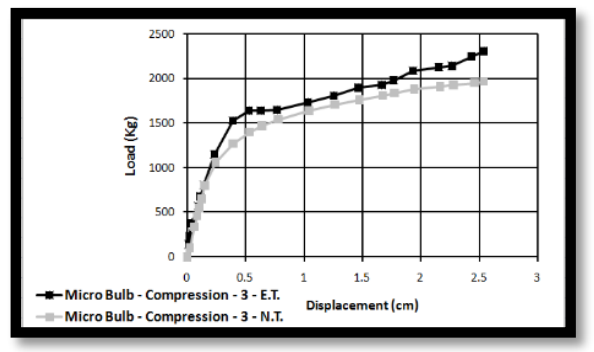

Figure 32. Comparison of laboratory test and numerical analysis of pressure bearing capacity of microbulb in soil with a density of 92 percent

As we can see in (Figure 32), the comparison of laboratory test and numerical test of pressure bearing capacity of microbulb with a density of 92 percent shows that the numerical diagram is the normalized form of laboratory diagram. Therefore, we can conclude that with the increase of amount of displacement and loading, the diagram for numerical test gets closer to the laboratory test diagram.
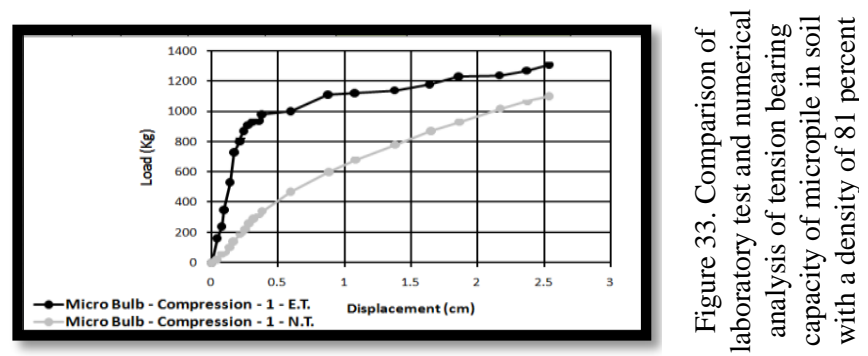
As we can see in (Figure 33), the comparison of laboratory test and numerical test of tension bearing capacity of micropile with a density of 81 percent shows that the numerical diagram is the normalized form of laboratory diagram. Therefore, we can conclude that with the increase of amount of displacement and loading, the diagram for numerical test gets closer to the laboratory test diagram.

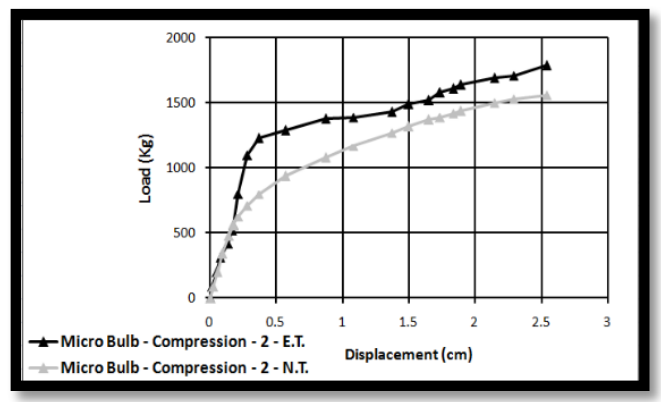

Figure 34. Comparison of laboratory test and numerical analysis of tension bearing capacity of micropile in soil with a density of 88 percent

As we can see in (Figure 34), the comparison of laboratory test and numerical test of tension bearing capacity of micropile with a density of 88 percent shows that the numerical diagram is the normalized form of laboratory diagram. Therefore, we can conclude that with the increase of amount of displacement and loading, the diagram for numerical test gets closer to the laboratory test diagram.

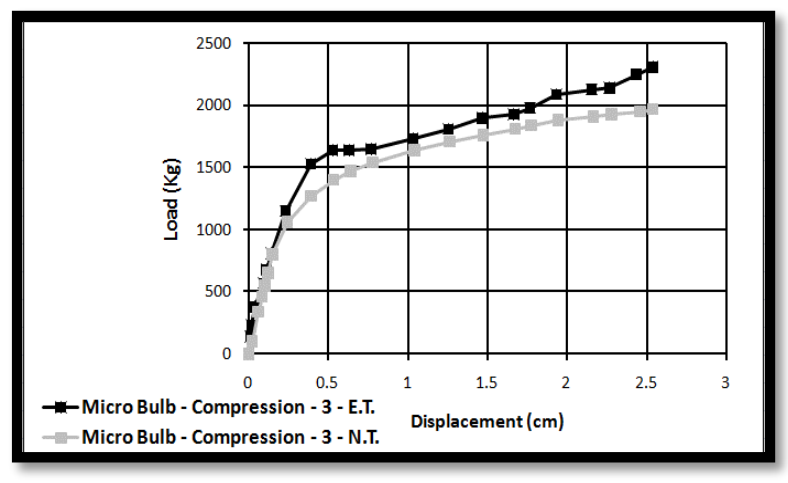

Figure 35. Comparison of laboratory test and numerical analysis of tension bearing capacity of micropile in soil with a density of 92 percent

As we can see in (Figure 35), the comparison of laboratory test and numerical test of tension bearing capacity of micropile with a density of 92 percent shows that the numerical diagram is the normalized form of laboratory. Therefore, we can conclude that with the increase of amount of displacement and loading, the diagram for numerical test gets closer to the laboratory test diagram.

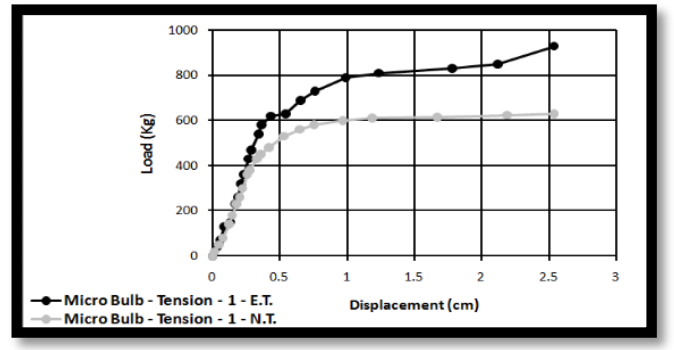

Figure 36. Comparison of laboratory test and numerical analysis of tension bearing capacity of microbulb in soil with a density of 81 percent

As we can see in (Figure 36), the comparison of laboratory test and numerical test of tension bearing capacity of microbulb with a density of 81 percent shows that the numerical diagram is the normalized form of laboratory diagram. Therefore, we can conclude that with the increase of amount of displacement and loading, the diagram for numerical test gets closer to the laboratory test diagram.

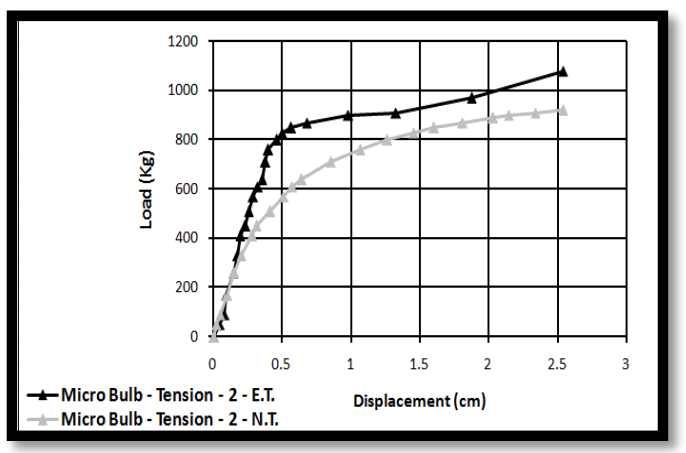

Figure 37. Comparison of laboratory test and numerical analysis of tension bearing capacity of microbulb in soil with a density of 88 percent

As we can see in (Figure 37), the comparison of laboratory test and numerical test of tension bearing capacity of microbulb with a density of 88 percent shows that the numerical diagram is the normalized form of laboratory diagram. Therefore, we can conclude that with the increase of amount of displacement and loading, the diagram for numerical test gets closer to the laboratory test diagram.

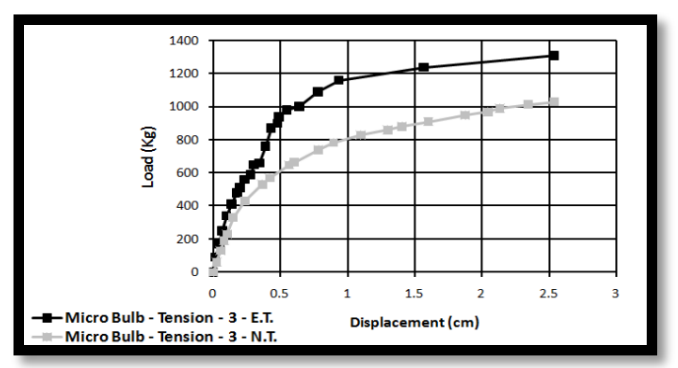

Figure 38. Comparison of laboratory test and numerical analysis of tension bearing capacity of micropile in soil with a density of 92 percent 
As we can see in (Figure 38), the comparison of laboratory test and numerical test of tension bearing capacity of microbulb with a density of 92 percent shows that the numerical diagram is the normalized form of laboratory diagram. Therefore, we can conclude that with the increase of amount of displacement and loading, the diagram for numerical test gets closer to the laboratory test diagram.

\section{CONCLUSION}

1-Generally, the application of microbulb instead of micropile increases the compression bearing capacity up to $95 \%$.

2-Generally, the application of microbulb instead of micropile increases the tension bearing capacity up to $60 \%$.

3-By the increase of soil density, the soil fixes more to the microbulbs and the the rate of compression bearing capacity and tension bearing capacity increases to some extent an then due to the impossibility for the bulbs to open the rate of increase of microbulb's bearing capacity reduces in comparison to the microplie.

4-The use of microbulb has a greater impact on compression bearing capacity in comparison with tension bearing capacity.

5-Carefull piercing of injection tubes has caused the injection process to be completed in a way that all areas around the micropile and microbulb will have the same function.

6-By reduction of water rate in comparison to the grout cement, the applied pressure can be increased from 3 to 3.6 times.

7- Increase in number of bulbs cause the increase of compression bearing capacity and tension bearing capacity, but this is effective for bulbs up to 3 , and as the number of bulbs increases up to 4 or 5 , this prevents the positive effect of lower micro bulbs. 8 -when the grout enters into the system, the tendency for grout absorption is higher in the upper bulbs and it is less for the lower bulbs.

9-Using less diameter holes in upper bulbs helps the bulbs to become the same size at the time of injection.

10-Using appropriate plastic mesh for protecting the bulbs leads to symmetric expansion of each bulb and control of rate of grout injection.

\section{ACKNOWLEDGEMENT}

We are thankful to the technical engineers of Plaxis Company Michca Vander Sloot and Michael Andriessen for their support and response during the modeling of microbulb. We would also like to express our deep gratitude to consulting engineers of Fahliyan Shiraz's company for sharing laboratory equipment's of strength of materials and soil mechanic.

\section{INVENTION}

The Expansible Bubled Micropile System was proposed by Mansour Mosala Nezhad, Saeed Hakimian and Abdollad Pourtangaki and it was approved scientifically at the Department of Science and Technology of Tehran University in 21 Feb. 2015 with the letter number of 139350740003009881 . This system was registered in 14 Jun. 2015 with the registration number of 85914, the International Classification of E02; E02D and certificate number A/89 037924 in Iran's intellectual property Center of Patent Office, Iran's state organization for registration of deeds and properties.

\section{References:}

Tom Armour, P.E.Paul Groneck,P.E.,James Keelev.P.E and Sunil Sharma,p.E.,PhD. (June,2000)." Micropile Design and construction Guidelines Implementation Manual Priority Technologies Program (PTP) Project", Sponsored by FHWA Office of Technology Applications, FHWA Federal Lands Highway Division Offices, FHWA.

Lizzi, F., (1985), 'Pali radice' (root piles and 'reticulated pali radice'), Underpining, Glasgow [Lanark]: Surrey University Press, 84-151.

Stuedlein, A.W. and Gibson, M.D. and Horvitz, G.E., (2008), "Tension and compression micropile load tests in gravelly sand", 6th International Conference on case histories in Geotechnical engineering, VA, Arlington, No1.12.

Han, J. and Ye, S.L., (2006), "A field study on the behavior of micropiles in sand under compression or tension" Canadian, Geotechnical, Journal, 43, pp. 19-29.

Reza Ziaie Moayed.and seyed Abolhasan Naeini,(2012),'Improvement of Loose Sandy Soil Deposit Using MicroPile",KSCE Journal Of Civil Engineering,Springer,334340.

Muhunthan, B., Shu, S., and Marek, A. R. (2005). "Sand state and performance analysis of micropiles", $\mathrm{PhD}$ Thesis, Washington State University, p. 158.

Sivakumar, G. L., Murthy, B., and Nataraj, M. S. (2004). "Bearing capacity improvement using micropiles: A case study". Proceedings, Geosupport Conference, pp. 692-699.

Armin W. Stuedlein, Matt D. Gibson, Garry E. Horvitz (2008) Hart Crowser, Inc. Seattle, Washington (USA) 98109.” Tension and compression micropile load test in gravelly sand". 6th international conference on case histories in geotechnical engineering in Arlington,VA, August 11-16, 2008.

Juran, I., Bruce, D.A., Dimillio, A., and Benslimane, A. (1999). "Micropiles: the state of practice. Part II: design of single micropiles and groups and networks of micropiles". Ground Improvement, 3, 89-110.

V.M Karpe, N. Dias, P.Y Sarang, (2011). "Micropiles an Innivative Ground Improvement Tools". International Journal of Earth Sciences and Engineering. pp 11-14. 
Kordahi, R. (2003) "Underpinning strategies for Buildings with Deep Foundation" M.E. dissertation, American University of Beirut.

Yamane, T., Nakata, Y., and Otani, Y. (2000). "Efficiency of micropile for seismic retrofit of foundation system" 12th World Conference on Earthquake Engineering, Auckland, New Zealand, pp .1-8.

Chango Choi,Sam-Deok Cho,(2009).” FIELD VERIFICATION STUDY FOR MICROPILE LOAD CAPACITY". Proceeding of Offshore and port technical group workshop, Korea Geotechnical Society, Seoul, Korea.

Choi, C., Goo, J-M., Lee, J-H, and Cho, S-D. (2009), "Development of New Micropiling Method Enhancing Frictional Resistance with Geotextile Pack", Proceeding of ISM 9th Workshop on Micropiles, London, May2009.

Young-Eun Jang, Jin-tae Han (2014)" Development on the Micropile for Applying to Artificial Ground above Railroad Site ", Advanced Science and Technology Letters Vol.55 (Architecture and Civil Engineering 2014), pp.43-46.

ASTM D422 (2008). Standard specification for "Particle-Size Analysis of Soils", American Society for Testing and Materials.

ASTM D3080 (2008). Standard specification for "Direct Shear Test for Soils", American Society for Testing and Materials.

ASTM D3080 (2008). Standard specification for "Laboratory Compaction Characteristic of Soil", American Society for Testing and Materials.

ASTM D4253 (2008). Standard specification for "Maximum Index Density and Unit Weight of Soils Using a Vibratory Table1", American Society for Testing and Materials.

ASTM D4254 (2008). Standard specification for "Minimum Index Density and Unit Weight of Soils and Calculation of Relative Density1", American Society for Testing and Materials.

Zienkiewicz O.C.,Taylor R.L (1991). "The Finite Element Method," (4thedition), Volume 2، Solid and Fluid Mechanic, Dynamic and Non Linearity.Mc Graw Hill, u.k.

Van Langen H. (1991), "Numerical analysis of soil-structure interaction". Dissertation. Delft University of Technology.

R.B.J. Brinkgreve \& W. Broere, (2005)," PLAXIS 3D FOUNDATION - version1.6". Delft University of Technology \& PLAXIS bv, The Netherlands.

Abbas Babaei, (2011)," Numerical investigation of axial bearing capacity of piles embedded in sloping ground". International Journal of the Physical Sciences Vol. 6(33), pp. 7589 - 7603.

Neves M, Mestat P, Frank R, Degny E (2001). "Research on the behavior of bored piles - I. in situ and laboratory experiments", CESAR-LCPC, 231: 39-54.

El-Mossallamy Y (2001). "Load-settlement Behavior of Large Diameter Bored Piles in Over-Consolidated Clay". Proceeding of
The 7th International Symposium on Numerical Models in Geotechnical Engineering, Graz, Austria. pp. 443-450.

Ismael NF (2001). "Axial Load Test Bored Piles and Pile Groups in Cemented Sands". J. Geotech. Geonviron. Eng., 127(9): 766773.

A.Alnuaim \& M.H.El.Naggar (2015). "Performance of micropiled raft in clay subjected to vertical concentrated load: Centrifuge modeling".Canadian Geotechnical Journal. November 2015, DOI: 10.1139/cgj-2014-0448.

Pere C. Prat (2016). "Numerical investigation into the failure of a micropile retaining wall". Dept. of Civil and Environmental Engineering, UPC-BarcelonaTECH, Spain, Computers and Geotechnics. 